\title{
TREATMENT IN GENERAL PRACTICE
}

\author{
This article is one of a series on the management of some of the major medical disorders met \\ with in general practice
}

\section{THE TREATMENT OF HAEMOPTYSIS}

\author{
BY \\ G. E. BEAUMONT, D.M., F.R.C.P.
}

When a doctor is called to attend a patient suffering from haemoptysis he should first inquire, if he is not already acquainted with the medical history of the patient, whether or not he is known to be suffering from pulmonary tuberculosis or any other disease which may give rise to haemorrhage from the lungs. In this country the most common causes of haemoptysis are pulmonary tuberculosis, mitral stenosis, and bronchiectasis. A very severe and rapidly fatal haemoptysis may be due to the rupture of an aneurysm into a bronchus.

The next step consists in the examination of the chest by inspection, palpation, and auscultation. Percussion must not be practised owing to the risk of increasing the bleeding. The heart should first be examined in order to determine whether or not mitral stenosis is present. In haemoptysis due to pulmonary tuberculosis, if the lesion is early, the physical signs are often very slight, and it may be difficult to decide from which side the bleeding is taking place. In such instances the patient may be able to say that he feels the blood coming from one side of the chest.

\section{Haemoptysis Due to Pulmonary Tuberculosis}

In all cases, whether slight or severe, the patient should go to bed until the bleeding has stopped.

\section{MILD CASES}

The treatment is usually easy in slight instances of haemoptysis, in which the sputum is tinged with blood, small clots are expectorated, or when small quantities of liquid blood are brought up. In addition to keeping the patient in bed until no more blood is apparent in the sputum, a morning and evening record of the temperature and pulse rate should be taken, to determine whether there is an indication of active tuberculosis. A determination of the sedimentation rate of the red cells of the blood will also afford a valuable indication as to activity.

During the continuance of the haemoptysis all food must be served cold, fluid should be restricted to two pints in the twenty-four hours, and the diet should consist of milk, jellies, custard, bread and butter, cold fish, and cold chicken. The bowels should be opened by magnesium sulphate $\mathfrak{j}^{\mathrm{ii}}$ in $\bar{j}^{\mathrm{ii}}$ of water mane, and if this is not efficacious a simple enema should be administered every other morning. Calcium should be given by mouth in some such preparation as collosol calcium (Crookes), $3 \mathrm{i}$ in water three times a day. This calcium should be continued for two to three months. When the bleeding has ceased, and if the temperature has been normal throughout, or after the first day or so, the patient may be allowed to get up and return to work a week later.

In all cases of haemoptysis due to pulmonary tuberculosis the patient must be warned that he must not expose his naked body to the sun, and preferably he should, when out of doors, sit in the shade. Undoubtedly cases of haemoptysis are more common in heat waves, when sun bathing is prevalent.

\section{MODERATELY SEVERE CASES}

Here the haemoptysis is usually indicative of activity of the tuberculous lesion. The temperature is raised and fails to return to normal in a day or so, and tubercle bacilli are at times found in the blood-stained sputum. The patient should be placed in bed, semi-recumbent on two pillows, and turned slightly to the side from which the bleeding is taking place, if this is known. He must be on " absolute rest," and not allowed to do anything for himself. He must be kept in a quiet room and no visitors allowed. An injection of $1 / 4$ grain of morphine sulphate should be given subcutaneously. Patients usually like to have a little ice to suck, and this may do good for psychological reasons. They also frequently appreciate the inhalation of a few drops of oil of turpentine from a handkerchief. If the bleeding persists a capsule of amyl nitrite (5 minims) should be broken under the patient's nostrils and the vapour inhaled. Further remedies which are of value in refractory cases consist in the intravenous injection of $1 \mathrm{c.cm}$. of collosol calcium (Crookes) daily, and the subcutaneous injection of 20 c.cm. of coagulen (Ciba) twice during the first day. The morphine may be repeated every six hours, but not more than 1 grain should be injected in twenty-four hours, owing to the risk of diminishing the cough reflex and causing the inhalation of infected material into healthy portions of the lungs. The injections of coagulen may be repeated in daily doses of $1.5 \mathrm{c} . \mathrm{cm}$. for a week, if necessary. In some protracted cases the daily intramuscular injection of 1 grain of emetine hydrochloride for twelve doses has proved of value.

\section{SEVERE CASES}

If these measures for the arrest of the haemorrhage are unsuccessful and the patient is in danger of losing his life, further active treatment is required. The thighs and upper arms should be bandaged sufficiently tightly to occlude the venous but not the arterial circulation. The bandages are applied first to the thighs for half an hour and then to the upper arms for half an hour. In the meanwhile preparations are made to induce an artificial pneumothorax on the affected side.

The initial or No. 1 artificial pneumothorax (A.P.) needle is sterilized by placing it in methylated spirit, and then holding it in forceps and lighting it in the flame of a spirit lamp. The sterilized needle is then placed in a kidney dish which has been sterilized by flaming. The patient is propped up in bed with two or three pillows, lying on his back with the arm abducted on the affected side. He should not be turned on to the sound side. The skin is painted with iodine in the mid-axilla. The sterilized skin in the fifth or sixth intercostal space in the mid-axilla is then anaesthetized with $2 \mathrm{c.cm}$. of 2 per cent. novocain solution, using for the skin and subcutaneous tissues a ery fine needle (No. 16) and then a larger one (No. 12) for the intercostal muscles and 
pleura. The pleura can usually be felt after the needle has penetrated through the muscles and a little novocain is injected into it. The needle is then partially withdrawn (so that it will not snap off at the hilt if the patient moves) and the syringe detached. After a few minutes the A.P. needle is attached to the rubber tube leading to the manometer of the A.P. apparatus, the novocain needle is taken out of the chest, and the A.P. needle inserted at the same spot. The initial needle consists of a trocar and cannula, and should be held between the thumb and middle finger, the index finger being pressed firmly on the top of the trocar as it is pushed through the skin and subcutaneous and muscular tissues. When the needle is judged to be nearly through the intercostal muscles the trocar is withdrawn, the tap of the needle is closed, and the cannula is pushed gently inwards until it is felt to reach the pleura. At this point a small swing can often be seen in the manometer. It is then gently pushed through the parietal layer of the pleura, when a good negative swing of the manometer should be obtained, such as $-7-14$, indicating that the end of the cannula is free in the pleural space. The clips on the rubber tubes of the A.P. apparatus are now released and air is allowed to. enter the pleura. Usually between $500 \mathrm{c} . \mathrm{cm}$. and $800 \mathrm{c.cm}$. are required to produce sufficient collapse of the lung to check a severe haemoptysis.

It should be remembered that in cases of haemoptysis in which an artery has eroded into a cavity there is no known treatment which will arrest the haemorrhage, and the patient dies in the space of a few minutes, having often expectorated a surprisingly small quantity of blood.

\section{Haemoptysis Due to Mitral Stenosis}

The cause of bleeding from the lung in these cases is probably a pulmonary thrombosis rather than passive venous congestion. The patient should be put to bed. If auricular fibrillation is present or the cardiac rate is unduly frequent, digitalis should be given in doses adequate to reduce the rate to about 80 a minute. The digitalis can be administered either in the form of the tincture, tablets of digitalis leaves, or as Nativelle's granules of digitaline. The average dose required for the first twenty-four to thirty-six hours is 30 minims of the tincture, three tablets ( 1 grain each) of the folia, or one granule (1/240 grain) of the digitaline. In any case the digitalis should not be given more frequently than every six hours, and if large doses are prescribed the apex rate should be counted before each dose is given in order to prevent an overdose.

The coagulability of the blood may be diminished by a mixture such as sodium citrate grains 30 , tinct. aurantii minims 5, aquam ad $\boldsymbol{z}^{\mathrm{i}}$, $\boldsymbol{\zeta}^{\mathrm{i}}$ t.d.s., or by applying two or three leeches over the skin of the chest, and by giving a grape-fruit every day.

\section{Haemoptysis Due to Bronchiectasis}

Recurrent attacks of pulmonary haemorrhage, slight or of some severity, may be the only symptom of bronchiectasis. The diagnosis is established by $x$-ray examination after the injection of lipiodol. There is generally little that can be done in the way of active treatment to check these recurrent haemoptyses, as frequently the bronchiectasis is central or near a main bronchus and resistant to collapse therapy. The bleeding is not usually severe enough to warrant a lobectomy. During the haemorrhage the patient should be kept in bed and treated on the lines described above for haemoptysis due to pulmonary tuberculosis.

\section{NEW YEAR HONOURS}

The list of New Year Honours was issued as a special supplement to the London Gazette on Tuesday, January 1st. The names of the following members of the medical profession are included.

\section{Baronet}

Sir Holburt J. Whring, C.B.E., M.S., F.R.C.S., President of the Royal College of Surgeons of England.

K.C.V.O.

Edmund Ivens Spriggs, M.D., F.R.C.P.

Knights Bachelor

Walter Langdon Brown, M.D., F.R.C.P., Regius Professor of Physic, University of Cambridge.

JoHN Boyd OrR, D.S.O., M.C., M.D., D.Sc., F.R.S., Director, Rowett Institute for Research in Animal Nutrition, Aberdeen.

Raphael West Cilento, M.D., Senior Medical Officer, Department of Health, Commonwealth of Australia.

Lieut.-Colonel JamshedjI Nasarvanji Duggan, C.I.E., O.B.E., L.M. and S., F.C.P.S.Bombay, D.O.Oxon, Professor of Ophthalmic Medicine and Surgery, Grant Medical College, Bombay, and Superintendent, C.J. Ophthalmic Hospital, Bombay.

\section{C.B. (Military)}

Major-General James Fitzgerald Martin, C.M.G., C.B.E., M.B. (late R.A.M.C.), Honorary Surgeon to the King, Deputy Director of Medical Services, Western Command, India.

\section{C.M.G.}

William ERNeST Jones, M.R.C.S., Director of Mental Hygiene, State of Victoria.

John Clarence Webster, M.D., D.Sc., LL.D., F.R.C.P.Ed., Archivist and member of the Historic Sites and Monuments Board of Canada.

Lieut.-Colonel Sydney Price James, M.D., F.R.S., Medical Officer and Adviser on Tropical Diseases, Ministry of Health, and Member of the Colonial Advisory Medical Committee.

\section{C.I.E.}

Lieut.-Colonel Edward Selby Phipson, D.S.O., Indian Medical Service, Civil Administrative Medical Officer, Health Officer of the Port of Aden, and Medical Officer, European General Hospital, Aden.

Major Henry James Rice, M.C., Indian Medical Service Military Hospital, Poona, attached to the Royal Deccan Horse.

\section{C.B.E. (Civil)}

Miss Catherine Chisholm, M.D., Physician, Manchester Northern Hospital for Women and Children.

David Llewelyn Williams, M.C., F.R.C.S.Ed., D.P.H., Medical Officer, Welsh Board of Health.

\section{O.B.E. (Military)}

Lieut.-Colonel George Duncan Ralph Black, V.D., M.D., lately Principal Medical Officer, Hong-Kong Volunteer Defence Corps.

O.B.E. (Civil)

Miss Edna Mary Guest, M.B., Chief of Department of Surgery, Women's College Hospital, Toronto.

Albert Reginald McLeod, M.D., Chief Staff Officer, St. John Ambulance Brigade, New South Wales.

Joseph Welsh Park Harkness, M.B., Deputy Director, Department of Health, Palestine.

Major Ahmad Khan Sahibzada, M.B., B.S., Indian Medical Service, Civil Surgeon, Hazara, North-West Frontier Province.

Percy Brigstocke, M.B., L.R.C.P., Chief Medical Officer of the Victoria Hospital, Damascus.

\section{M.B.E}

Alexander Jardine Hunter, M.D., for services as missionary-physician in pioneer settlements of Manitoba, Canada.

James Douglas Alleyne, M.D., Port Health Officer, Barbados. 